\title{
Congenital heart disease in Africa threatens Sustainable Development Goals
}

Labaekas $^{[1]}$ case study in this issue of the SAJCC describes the fatal outcome of a baby presenting late, in extremis, with transposition of the great arteries. This is a typical example of what many African parents face when their newborn baby is diagnosed with complex congenital heart disease (CHD).

$\mathrm{CHD}$ is the most common birth defect, and is associated with higher mortality than any other congenital abnormality. ${ }^{[2]}$ In Africa, late presentation of $\mathrm{CHD}$ is the norm. ${ }^{[3,4]}$ Complications due to multi-organ involvement usually prompt the families to seek medical advice. Once the baby presents with established organ dysfunction, decision-making around early timed treatment and surgery becomes critically complex. ${ }^{[2]}$

Pulse oximetry, an easy and inexpensive screening strategy, can help to diagnose complex $\mathrm{CHD}$ at birth and alert healthcare workers to direct babies timeously for further assessment before complications develop. ${ }^{[4,5]}$

Access to affordable comprehensive cardiac healthcare is restricted to a handful of specialised cardiac centres on the African continent. A few lucky children receive treatment from philanthropic fly-in-fly-out medical missions sponsored by high-income countries (HICs). However, this healthcare model is not sustainable unless long-term co-operation and education programmes are established between local and international healthcare teams. The only alternative treatment option for families is to send their baby to specialised paediatric cardiac centres abroad. This is unfortunately unaffordable for the majority of African families. ${ }^{[3]}$

Worldwide, the prevalence of CHD is estimated at 1.8 per 100 live births, according to the 2017 Global Burden of Diseases, Injury and Risk Factor (GBDIRF) study funded by the Bill \& Melinda Gates Foundation. Approximately 261247 people died of CHD during the study year, and $69 \%$ of the deaths occurred in children $<1$ year old. ${ }^{[6]}$

Despite the seemingly high mortality, CHD treatment has been one of modern medicine's greatest success stories. Management of CHD has grown from the first pioneers creating the Blaloch-Taussig shunt for tetralogy of Fallot in the 1940s, to the present-day subspecialty of paediatric cardiac critical care and dedicated paediatric cardiac intensive care units.

There are currently more adult survivors worldwide living with complex congenital heart lesions than children. ${ }^{[7,8]}$ The 2017 GBDIRF study found that about 12 million people are living with CHD worldwide ${ }^{[5]}$ Survival has become the norm in HICs, and nowadays medical treatment is focused on improving quality of life by reducing morbidity. ${ }^{[2,8]}$

In HICs, $85 \%$ of all children with CHD survive to adulthood. Almost 95\% of children with simple CHD lesions such as ventricular septal defect, and $90 \%$ of moderate complex CHD such as tetralogy of Fallot or neonatal coarctation, survive long term. Currently, $\sim 80 \%$ of children with complex CHD such as transposition of the great arteries or truncus arteriosus survive to adulthood in HICs. ${ }^{[8]}$

Despite the $34.5 \%$ reduction in global CHD mortality during the past decade, Africa's CHD deaths have increased. The increased mortality is linked to poverty and limited access to appropriate treatment. ${ }^{[4]}$ During the past decade, CHD mortality has increased in the central, eastern and western sub-Saharan regions by $38.1 \%, 4.6 \%$ and $40.3 \%$, respectively. Southern sub-Saharan Africa was the only region that demonstrated a decline in CHD deaths of $20.1 \% .{ }^{[6]}$
Furthermore, the GBDIRF study ${ }^{[6]}$ found a $4.2 \%$ global increase in birth prevalence of CHD between 1990 and 2017. Expanded paediatric cardiology, cardiac surgery and cardiac critical care services are required to treat the increasing number of children born with CHD. In particular, low- and middle-income countries (LMICs) lack sufficient paediatric cardiology, cardiac surgery and cardiac critical care infrastructure and expertise to cope with the increasing burden of CHD. ${ }^{[3,9-11]}$

Currently, there are only 22 cardiac centres in Africa performing a mean of 18 open heart surgeries per million people, compared with 169 per million people worldwide. ${ }^{[10]}$ Reports estimate that around $90 \%$ of all children in Africa with CHD do not have access to appropriate medical care. ${ }^{[12,13]}$ Without proper medical treatment, approximately one-third of the children born with moderate and severe CHD will not survive beyond the neonatal period, and half will die in early infancy. ${ }^{[13]}$ Without appropriate treatment, those who do survive beyond infancy will suffer debilitating complications. ${ }^{[4,14,15]}$

The Sustainable Development Goals (SDGs), signed by all members of the United Nations in 2015, aim to reduce neonatal and under-5 mortality by $2030{ }^{[16]}$ Successful programmes addressing communicable diseases such as HIV, TB and malaria, and childhood immunisation, are examples of what can be accomplished in Africa. ${ }^{[17,18]}$ Following pneumonia, diarrhoeal disease and birth conditions, CHD is the seventh-most common cause of childhood mortality in Africa. ${ }^{[6]}$ Unfortunately, among these competing healthcare needs in Africa, CHD has received very little priority compared with communicable diseases. ${ }^{[17,18]}$

Political leaders need to be made aware that cost-effective CHD treatment can be implemented in Africa with successful longterm outcomes. ${ }^{[13,17]}$ Schidlow et al. ${ }^{[19]}$ describe excellent outcomes for children with complex CHD in LMICs. This study, from the International Quality Improvement Collaborative for Congenital Heart Surgery in Developing World Countries, showed 85\% early survival after corrective surgery for transposition of the great arteries (778 operations) in 26 paediatric cardiac centres in developing countries across the world. Uganda was the only African nation included in this report. Edwin et al. ${ }^{[20]}$ showed that even late surgery for transposition of the great arteries can be done successfully in a specialised paediatric cardiac surgery centre in Africa.

Given the increase in CHD prevalence and the consequent increase in mortality, sustainable CHD treatment should be prioritised as a major focus towards reaching the SDGs in Africa. Failing to build this capacity, CHD may become a major contributor to missing the 2030 SDG target.

\author{
B Rossouw, MB ChB, DTM\&H (SA), MMed (Paed), Cert Crit \\ Care (Paed), Cert Cardiol (Paed), DPC \\ Paediatric Intensive Care, Department of Paediatrics and Child Health, \\ Red Cross War Memorial Children's Hospital and University of Cape \\ Town, South Africa \\ beyra.rossouw@uct.ac.za
}


1. Labaeka AA. Delayed presentation of transposition of the great arteries with intact ventricular septum in an 8-week-old male infant at University College Hospital in Ibadan, Nigeria. S Afr J Crit Care 2021;37(1):37-39. https://doi.org/10.7196/SAJCC.2021.v37i1.XXX

2. Iyer PU, Moreno GE, Caneo LF, Faiz T, Shekerdemian L. Management of late presentation congenital heart disease. Cardiol Young 2017;27:s31-s39. https://doi.org/10.1017/s1047951117002591

3. Edwin F, Zuhlke L, Farouk H, et al. Status and challenges of care in Africa for adults with congenital heart defects. World J Pediatr Congenit Heart Surg 2017;8(4):495-501. https://doi. org/10.1177/2150135117706340

4. Zimmerman M, Sable C. Congenital heart disease in low-and-middle-income countries: Focus on sub-Saharan Africa. Am J Med Genet C Semin Med Genet 2020;1-11. https://doi.org/10.1002/ ajmg.c.31769

5. Mahle WT, Newburger JW, Matherne GP, et al. Role of pulse oximetry in examining newborns for congenital heart disease: A scientific statement from the AHA and AAP. Pediatrics 2009;124(2):823-836

6. Zimmerman MS, Smith AGC, Sable CA, et al. Global, regional, and national burden of congenital heart disease, 1990 - 2017: A systematic analysis for the Global Burden of Disease Study 2017. Lancet Child Adolesc Health 2020;4(3):185-200. https://doi.org/10.1016/s23524642(19)30402-x

7. Warnes CA, Liberthson R, Danielson GK, et al. Task force 1: The changing profile of congenital heart disease in adult life. J Am Coll Cardiol 2001;37(5):1170-1175. https://doi.org/10.1016/ s0735-1097(01)01272-4

8. Marino BS, Lipkin PH, Newburger JW, et al. Neurodevelopmental outcomes in children with congenital heart disease: Evaluation and management - a scientific statement from the American Heart Association. Circulation 2012;126(9):1143-1172. https://doi.org/10.1161/ cir.0b013e318265ee8a

9. Bolman R, Urban A, Thameur H, et al. Cardiac surgery capacity in sub-Saharan Africa: Quo vadis? Thorac Cardiovasc Surg 2014;62(05):393-401.

10. Zilla P, Yacoub M, Zuhlke L, et al. Global unmet needs in cardiac surgery. Glob Heart 2018;13(4):293-303. https://doi.org/10.1016/j.gheart.2018.08.002
11. Bronicki RA, Pollak U, Argent AC, et al. Global perspective on training and staffing for paediatric cardiac critical care. Cardiol Young 2017;27(S6):S9-S13. https://doi.org/10.1017/ s1047951117002566

12. Penny DJ. Global perspectives on pediatric cardiac critical care. Pediatr Crit Care Med 2016;17(8 Suppl 1):S388-393. https://doi.org/10.1097/pcc.0000000000000784

13. Zheleva B, Atwood JB. The invisible child: childhood heart disease in global health. Lancet 2017;389(10064):16-18. https://doi.org/10.1016/s0140-6736(16)32185-7

14. Hewitson JZ, P. Children's heart disease in sub-Saharan Africa: Challenging the burden of disease. SA Heart 2010;7(1):18-29. https://doi.org/10.24170/7-1-1964

15. Sileshi L, Tefera E. Health-related quality of life of mothers of children with congenita heart disease in a sub-Saharan setting: Cross-sectional comparative study. BMC Res Notes 2017;10(1):513. https://doi.org/10.1186/s13104-017-2856-6

16. Morton S, Pencheon D, Squires N. Sustainable Development Goals (SDGs), and their implementation: A national global framework for health, development and equity needs a systems approach at every level. Br Med Bull 2017;124(1):81-90. https://doi.org/10.1093/bmb/ $1 \mathrm{dx} 031$

17. Edwin F, Elgamal M-A, Dorra A, et al. Challenges of caring for functionally single ventricle patients in Africa. World J Pediatr Congenit Heart Surg 2019;10(3):338-342. https://doi. org/10.1177/2150135118817769

18. Mocumbi AO. The challenges of cardiac surgery for African children. Cardiovasc J Afr 2012;23(3):165-167. https://doi.org/10.5830/cvja-2012-013

19. Schidlow DN, Jenkins KJ, Gauvreau K, et al. Transposition of the great arteries in the developing world: Surgery and outcomes. J Am Coll Cardiol 2017;69(1):43-51. https://doi. org/10.1016/j.jacc.2016.10.051

20. Edwin F, Kinsley RH, Mamorare H, Colsen P. Late primary arterial switch for transposition of the great arteries with intact ventricular septum in an African population. World J Pediatr Congenit Heart Surg 2011;2(2):237-242. https://doi.org/10.1177/2150135110395335 